\title{
Pedestrian-motorcycle collisions: associated risks and issues
}

\author{
Aqbal Hafeez Ariffin ${ }^{1, *}$, Azhar Hamzah ${ }^{1,2}$, Mohd Syazwan Solah ${ }^{1}$, Noor Faradila Paiman ${ }^{1}$, \\ Siti Fairos Mat Hussin ${ }^{1}$ and Mohd Rasid Osman ${ }^{1}$ \\ ${ }^{1}$ Vehicle Safety and Biomechanics Research Centre, Malaysian Institute of Road Safety Research \\ (MIROS), Lot 125-135, Jalan TKS 1, Taman Kajang Sentral, 43000 Kajang, Selangor, Malaysia \\ ${ }^{2}$ MIROS PC3 Crash Laboratory, KM 15 Jalan Tiang Dua, 75450 Ayer Molek, Melaka, Malaysia
}

\begin{abstract}
From the statistics, there are serious concerns over the relatively high number of fatal motor vehicle crashes involving pedestrianmotorcycle in Malaysia. The high number of motorcycle registration on road, compounded by its popularity as the major mode of transportation in the nation, imposes safety risk to pedestrians, as well as to other road users. Data from 1,626 related road crashes of Royal Malaysia Police (RMP) for the 2009-2013 period were retrospectively collected via MIROS Road Accident Analysis and Database System (M-ROADS). The data were then analyzed via logistic regression method to determine associations between risks and injury severity in pedestrian-motorcycle collisions. The results indicate that five factors were significantly related to injury severity, which include age, location of body injury, as well as speed limit, road geometry and lighting condition of collision site. Subsequently, focus group discussions with stakeholders were also conducted to gather relevant data to identify related issues and suggestions on motorcycle safety technology with regards to collision with pedestrian.
\end{abstract}

\section{Introduction}

\subsection{Overview of road crash statistics}

According to the World Health Organization's (WHO) Global status report on road safety 2015, almost half of the estimated 1.25 million deaths of the world's roads per year are among those with least protection, i.e. vulnerable road users (VRU) which include motorcyclists $(23 \%)$, pedestrians $(22 \%)$ and cyclists (4\%) (Fig. 1). The casualty statistics concerning VRUs are not just apparent in most low- and middle-income countries, but also in high-income countries such as European countries, the United States, the United Kingdom, China, Japan and Republic of Korea [1-4]. Comparable situation can be observed in Malaysia with motorcyclists $(62.1 \%)$ and pedestrians $(6.6 \%)$ constituted more than twothird of total road fatalities in 2013 and the fraction is almost the same each year [5-8].

*Corresponding author: aqbal@miros.gov.my 


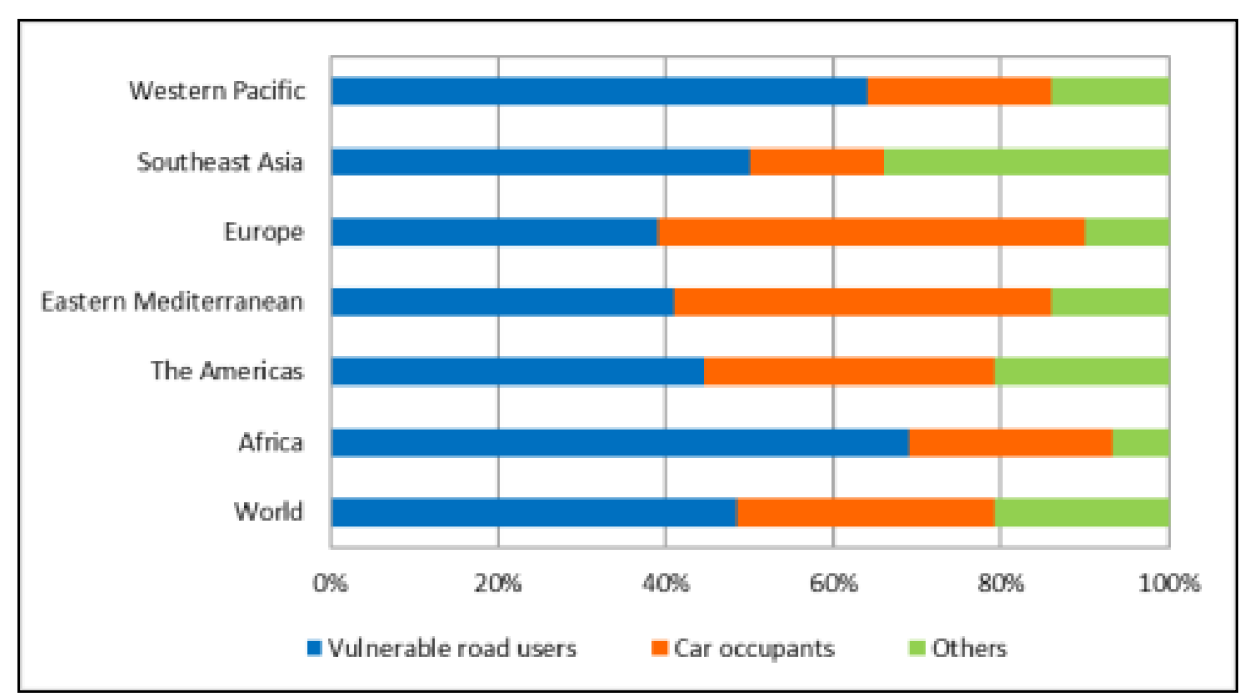

Fig. 1. Reported deaths by type of road user (\%), by WHO region [3].

An analysis conducted for the past 10-year period (2001-2010) of local motorcycle crash data showed that motorcyclists were involved in $24.8 \%$ of killed and severely injured (KSI) crashes involving collision with pedestrian (by type of first collision) [9]. Aqbal Hafeez et al. (2010) in their study of pedestrian casualties in road crashes in Malaysia found motorcycles as the second-most striking crash opponents in single vehicle accident (SVA) with fatal single pedestrian after M1 and M2 category passenger vehicles (e.g. cars, vans, 4 WDs). Nevertheless, for the same crash configuration, the study revealed most killed and severely injured pedestrians were struck by motorcycles $(54 \%)$ followed by passenger vehicles $(40 \%)$.

\subsection{Road safety plan}

In March 2010, the UN General Assembly proclaimed the Decade of Action (DOA) for Road Safety 2011-2020; it was subsequently launched globally on 11 May 2011, with the aim of reducing and stabilising road traffic fatalities worldwide by 2020 [10]. The DOA plan rests on five pillars in which one of them (Pillar 3) focusing on safer vehicles. Two related activities were set for elevating the safety of motorcycles and pedestrians by encouraging universal deployment of crash avoidance technologies such as Electronic Stability Control (ESC) and Antilock Braking System (ABS) in motor vehicles, and application of pedestrian protection regulations and increased research into safety technologies designed to reduce risks to VRUs. Similar programme has been adopted and outlined in the second Road Safety Plan Malaysia (RSPM) 2014-2020 to encourage implementations of UN Regulations through Vehicle Type Approval (VTA) which is by promotion of safety technology use for motorcycle (active safety e.g. ABS, ESC, lighting and signaling, passive safety e.g. crashworthiness) to reduce crash risk to motorcyclist as well as pedestrian and other road users [11].

\subsection{Motivation of study and its importance}

At present, to the best of knowledge of the author, limited study has been carried out concerning pedestrian-motorcycle collision safety either on worldwide or on Malaysia level, i.e. severity of the issue is unknown. From the statistics, there are serious concerns 
over the relatively high number of road accidents involving pedestrian-motorcycle in Malaysia. As reported by Road Transport Department, motorcycle constitutes almost half of total registered vehicles (46\% of total 24.8 million registered vehicles) and its registration increases each year [12]. This, the high number of motorcycle registration on road, compounded by its popularity as the major mode of transportation in the nation, imposes risk to pedestrians, as well as to other road users. Based on the above point of views, a need exists to foster a great understanding of pedestrian-motorcycle crashes due to the worrying abovementioned crash statistics. Other than to investigate the characteristics of the said road crash, this study aims to identify via statistical analysis the associated risk factors that caused for road crashes involving pedestrian and motorcycle. Findings obtained from this study will provide vital information to the government and the motorcycle industry for improvement of related safety measures. Moreover, this study is expected to be a piece of useful reference for subsequent related researches.

\section{Methodology}

\subsection{Data source, selection and description}

The source of the road accident data was retrospectively obtained from the MIROS Road Accident Analysis and Database System (M-ROADS) which contains comprehensive accident data collected throughout the nation by the Royal Malaysia Police (RMP) Traffic Department. The form used by the police for the data collection is a road accident form known as POLIS 27 (POL 27) which contains a total of 91 variables comprising various information on the crash characteristics, the casualties and the vehicles involved. This study used a five-year data from 2009 through 2013 due to the data completeness at the time of the study was initiated. Dataset for this study includes fatal and non-fatal (severe and slight injuries) cases involving single injured pedestrians in single-vehicle accidents, i.e. one pedestrian struck by one motorcycle. The non-injury cases were omitted to maintain data accuracy and to avoid probable insufficient data due largely to underreporting. The final dataset contained a total of 1,626 related cases throughout Malaysia for the study period. Out of the figure, $18.0 \%(n=293)$ contributed to fatal cases, $29.3 \%(n=477)$ was severe injury cases and slight injury cases comprised of $52.6 \%(n=856)$.

\subsection{Statistical analysis}

The current study focuses only on fatal and injury cases to pedestrian only (injury to motorcycle rider was not examined) to analyze factors contributing to the injuries. The data were filtered and analyzed using SPSS software version 17.0. Logistic regression technique was used to estimate the relative risks by approach of odds ratios (OR) at $95 \%$ confidence intervals (CI). An OR value that is greater than 1 indicates higher risk to the concerned attribute and vice versa. The pedestrian injury severity was divided into two injury levels which are fatal (attribute; coded as ' 1 ') and non-fatal (control; coded as '0') for the purpose of performing logistic regression that required for a binary typed outcome. Univariate logistic regression was performed for each selected predictor variable to identify potential risk factors which significantly influence the probability of injury to pedestrian. Multivariate logistic regression was then employed to develop injury risk model by taking consideration the effects of other predictor variables identified during the univariate analysis. The model was estimated manually to determine the variables that to be included in the final model. Entry and removal probabilities for the stepwise procedure were both set 
at 0.05 and 0.10 , respectively. The dependent and independent variables considered in this study are summarized as follow:

Table 1. Description of variables selected for the analysis.

\begin{tabular}{|c|c|c|}
\hline Factors & Categories & Variables and coding \\
\hline Dependent variable & Injury severity & $\begin{array}{l}0: \text { Non-fatal injuries } \\
1: \text { Fatal }\end{array}$ \\
\hline Pedestrian & $\begin{array}{l}\text { Age } \\
\text { Body injury location } \\
\text { Pedestrian location } \\
\text { Pedestrian action }\end{array}$ & $\begin{array}{l}0: \leq 25 \text { years old } \\
1: 26-64 \text { years old } \\
2:>64 \text { years old } \\
0: \text { Others } \\
1: \text { Head injury } \\
0: \text { Others } \\
1: \text { On roadways } \\
2: \text { At pedestrian crossings } \\
0: \text { Others } \\
1: \text { Crossing road/junction }\end{array}$ \\
\hline Environment & $\begin{array}{l}\text { Speed limit } \\
\text { Road geometry } \\
\text { Lighting condition }\end{array}$ & $\begin{array}{l}0:<50 \mathrm{~km} / \mathrm{h} \\
1: 50 \mathrm{~km} / \mathrm{h} \\
2:>50 \mathrm{~km} / \mathrm{h} \\
0: \text { Others (junctions, roundabouts) } \\
\text { 1: Curved } \\
\text { 2: Straight } \\
0: \text { Daylight } \\
\text { 1: Dawn/Dusk } \\
\text { 2: Dark-lit } \\
\text { 3: Dark-unlit }\end{array}$ \\
\hline Vehicle (Motorcycle) & $\begin{array}{l}\text { Motorcycle's age } \\
\text { Engine capacity }\end{array}$ & $\begin{array}{l}0:<5 \text { years } \\
1: 5-9 \text { years } \\
2:>9 \text { years } \\
0:<151 \mathrm{cc}(\text { underbone) } \\
1:>150 \mathrm{cc}\end{array}$ \\
\hline
\end{tabular}

\subsubsection{Logistic regression}

As illustrated in numerous literatures, logistic regression is an imperative statistical method especially in road safety, in analyzing road accident data. It has been widely used by researchers to determine the factors associated with the cause of road accident and the resulted injury severities [e.g. 8, 13-15]. This regression method allows for prediction of a binary outcome from a set of explanatory dependent variables from recorded accident data which is normally categorical.

\subsection{Focus group discussion}

Interviews and technical discussions via FGD with experts from local motorcycle industry (assemblers and distributors) were conducted to explore their views and suggestions on motorcycle-related safety towards motorcycle-pedestrian collision. The selected assemblers and distributors are Boon Siew Honda, Suzuki Assemblers, Modenas, Hong Leong Yamaha Motor and Kawasaki Motors. 


\section{Results and discussion}

\subsection{Injury severity analysis}

The following table describes the frequencies and ORs of risk factors to pedestrians.

Table 2. Univariate and multivariate logistic regression results with ORs (95\% CI).

\begin{tabular}{|c|c|c|c|}
\hline Factors & $\begin{array}{c}\text { Frequency } \\
\text { n (\%) }\end{array}$ & $\begin{array}{c}\text { Unadjusted ORs } \\
(95 \% \text { CI) }\end{array}$ & $\begin{array}{c}\text { Adjusted ORs } \\
(95 \% \text { CI })\end{array}$ \\
\hline \multicolumn{4}{|l|}{ Age } \\
\hline$\leq 25$ years old (control) & $824(50.7)$ & & \\
\hline $26-64$ years old & $556(34.2)$ & $6.95(4.72,10.23) *$ & $9.78(5.59,17.11) *$ \\
\hline$>64$ years old & $246(15.1)$ & $21.89(14.42,33.22)^{*}$ & $30.72(17.01,55.47)^{*}$ \\
\hline \multicolumn{4}{|l|}{ Body injury location } \\
\hline Others (control) & $1,135(70.9)$ & & \\
\hline Head injury & $465(29.1)$ & $6.94(5.27,9.13)^{*}$ & $6.22(4.20,9.20)^{*}$ \\
\hline \multicolumn{4}{|l|}{ Pedestrian location } \\
\hline Others (control) & $819(51.2)$ & & \\
\hline On roadways & $737(46.0)$ & $1.47(1.13,1.90)^{*}$ & - \\
\hline At pedestrian crossings & $45(2.8)$ & $1.57(0.76,3.25)$ & - \\
\hline \multicolumn{4}{|l|}{ Pedestrian action } \\
\hline Others (control) & $583(36.4)$ & & \\
\hline Crossing road/junction & $1,018(63.6)$ & $1.58(1.20,2.09)^{*}$ & - \\
\hline \multicolumn{4}{|l|}{ Speed limit } \\
\hline$<50 \mathrm{~km} / \mathrm{h}$ (control) & $576(35.4)$ & & \\
\hline $50 \mathrm{~km} / \mathrm{h}$ & $414(25.5)$ & $1.21(0.85,1.73)$ & $1.49(0.88,2.54)$ \\
\hline$>50 \mathrm{~km} / \mathrm{h}$ & $636(39.1)$ & $1.95(1.45,2.64)^{*}$ & $1.56(1.00,2.44)^{*}$ \\
\hline \multicolumn{4}{|l|}{ Road geometry } \\
\hline Others (control) & $106(6.6)$ & & \\
\hline Curved & $89(5.5)$ & $0.50(0.24,1.01)$ & $0.53(0.19,1.50)$ \\
\hline Straight & $1,412(87.9)$ & $0.57(0.37,0.89)^{*}$ & $0.41(0.20,0.85)^{*}$ \\
\hline \multicolumn{4}{|l|}{ Lighting condition } \\
\hline Daylight (control) & $1,147(70.7)$ & & \\
\hline Dawn/Dusk & $88(5.4)$ & $1.71(1.01,2.90)^{*}$ & $1.46(0.64,3.33)$ \\
\hline Dark-lit & $229(14.1)$ & $2.07(1.48,2.90) *$ & $1.10(0.66,1.85)$ \\
\hline Dark-unlit & $158(9.7)$ & $2.32(1.58,3.40)^{*}$ & $2.03(1.16,3.57)^{*}$ \\
\hline \multicolumn{4}{|l|}{ Motorcycle's age } \\
\hline$<5$ years (control) & $694(53.4)$ & & \\
\hline $5-9$ years & $276(21.2)$ & $1.05(0.73,1.50)$ & - \\
\hline$>9$ years & $330(25.4)$ & $1.06(0.76,1.49)$ & - \\
\hline \multicolumn{4}{|l|}{ Engine capacity } \\
\hline$<151 \mathrm{cc}$ (control) & $1,270(98.1)$ & & \\
\hline$>150 \mathrm{cc}$ & $25(1.9)$ & $1.81(0.75,4.38)$ & - \\
\hline
\end{tabular}

* Statistically significant at the 0.05 level.

Univariate analysis revealed the variables of age, body injury location, pedestrian action, speed limit, road geometry, and lighting condition as significantly correlated with the dependent variable - possible important factors affecting injury severity. Nevertheless, motorcycle's age (calculated at time of accident based on year) and engine capacity was found insignificant despite being included in the analysis. Gender was also an unimportant factor.

Pedestrian age: Pedestrians 65 years old and above had the highest odds of death as compared to pedestrians between ages of 26 and 64. The former group of pedestrians were 
also involved in 50 percent of pedestrian fatalities, higher than the latter group's percentage $(24.1 \%)$.

Body injury location: The odds of fatal for pedestrians with head injuries was nearly 7 times greater than those suffered other body injury locations.

Pedestrian location: Pedestrians at dedicated crossing areas and on roadways faced 1.57 and 1.47 times more risk of being fatal in road accident as compared to on other impact locations.

Pedestrian action: Pedestrians who cross the road/junction faced 1.58 times more risk of getting killed in road accident as compared to other actions.

Speed limit: The odds of death at the scene with speed limit of $>50 \mathrm{~km} / \mathrm{h}$ and $50 \mathrm{~km} / \mathrm{h}$ were 1.95 and 1.21 times greater, respectively, than with speed limit of $<50 \mathrm{~km} / \mathrm{h}$.

Road geometry: Pedestrians who were involved in road accidents on straight roads were 0.57 times less likely to be fatal than those on other road geometries, such as such as junctions and roundabouts.

Lighting condition: Insufficient light especially during dawn/dusk $(\mathrm{OR}=1.71)$, dark with $(\mathrm{OR}=2.07)$ or without streetlight $(\mathrm{OR}=2.32)$ posed higher risk of fatal outcome to pedestrians as opposed to road accidents occurred in daylight. Greater risk of fatal to pedestrians involved in road accidents that take place in ill-lit areas (dark without street lightings $)(\mathrm{OR}=2.32)$ as opposed to road accidents occurred in daylight.

Risk factors which were statistically significant were included and their significance were assessed in the final model. Multivariate analysis showed that pedestrian location and action during collision with motorcycle were not significant variables and were further removed from the model. Similar risk factors were observed significant when comparing the results with the previous analysis. Pedestrian age remained significant and showed approximately $40 \%$ increase in ORs (from 6.95 to 9.78 and from 21.89 to 30.72 for 26-64 years old and $>64$ years old, respectively) in the final model. Several other factor levels even had close ORs although there were also relative differences between them. Head injury, speed limit $>50 \mathrm{~km} / \mathrm{h}$, straight road and ill-lit condition (dark-unlit) were also significant factors that increased the risk of fatal to pedestrians, but with slightly lower adjusted ORs as compared to those unadjusted.

\subsection{Motorcycle-pedestrian safety from industry perspective}

FGDs with local motorcycle industry revealed several invaluable information on motorcycle-pedestrian safety issues and suggestions as summarized in the following points.

- Pedestrian-motorcycle collision is a unique road safety issue especially in Malaysia where motorcycle registration accounted for almost half of the total vehicle registration.

- Crash avoidance technologies such as Antilock Brake System (ABS) and Automated Emergency Braking (AEB) pedestrian are some of the effective safety systems in passenger cars that can probably be incorporated into motorcycles to assist in preventing road collision between motorcycles and pedestrians.

- Potential design of "forgiving" structure (passive safety) through pedestrian protection regulations can be included for motorcycles to protect pedestrians and reduce the severity of injury in the event of collision. However, the design elements should not disregard the safety of motorcycle rider and pillion.

- There is no requirement in the local legislation for addressing pedestrian protection with respect to collision with motorcycle. With respect to ABS for motorcycle, some countries and region (European Union and Brazil) have started to mandate the related legislation for all new motorcycles over $125 \mathrm{cc}$ (Fig. 2). Whereas, manufacturers will have an option to provide either ABS of Combined Brake System (CBS) onto motorcycles with engine capacity under $125 \mathrm{cc}$. There is a possibility for other countries 
especially those with high number of accidents involving motorcycles to follow this example by making the legislation compulsory.

- Until recently, several motorcycle models of large engine capacity ( $>250 \mathrm{cc}$ ) have been equipped with ABS. As for small engine capacity especially 'underbone' motorcycles $(\leq 150 \mathrm{cc})$, very limited models are possibly equipped with such safety system.

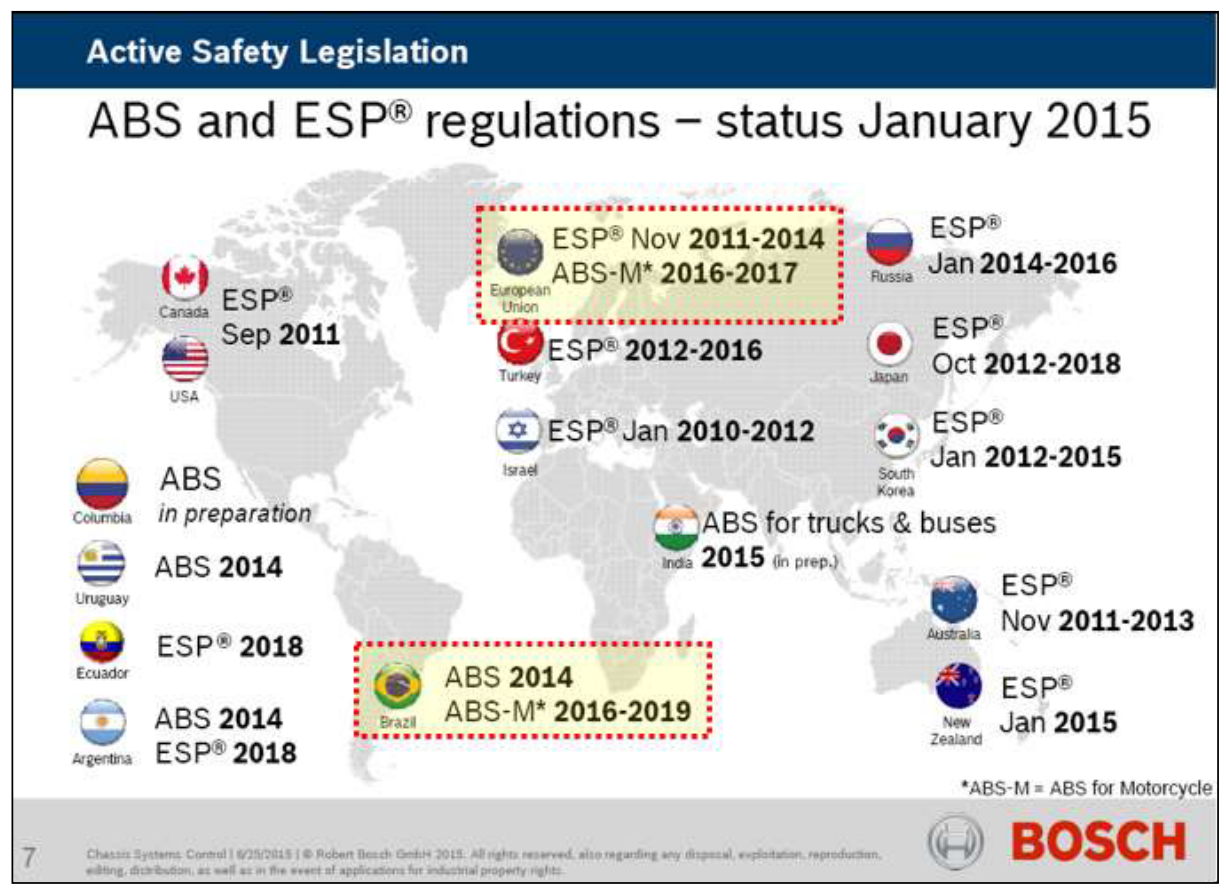

Fig. 2. ABS and ESP legislations status worldwide [16].

\section{Conclusions}

This study identifies risk factors that influence pedestrian injury severity in road collision with motorcycle via retrospective method by utilizing police-reported crash records. Results of the logistic regression analysis conducted on the dataset revealed age ( $>25$ years old), body injury location (head), speed limit $(>50 \mathrm{~km} / \mathrm{h})$, road geometry (straight) and lighting condition (dark-unlit) as significant factors (in the final model) that led to a noticeably higher risk of pedestrian mortality. Discussions with motorcycle industry suggested inclusion of crash avoidance technologies (e.g. ABS and AEB) onto motorcycle as one of the possible vehicle engineering measures to reduce this type of road collision. Nevertheless, utilization of data from related in-depth accident investigations should be conducted to improve the overall analysis since this study is limited by the variables that are readily available in POL 27 - inadequate information on crash configuration (front, side, etc.) and detailed vehicle damage. Last but not least, the identification of these risk factors provides crucial information for interventions and safety control measures that help to prevent and mitigate casualties and injuries resulted from the pedestrian-motorcycle collisions, hence improve the road safety level in the country.

The authors would like to express their great appreciation to MIROS for granting this research work. Acknowledgements also go to RMP and the experts from motorcycle industry for the relevant road crash data and invaluable technical information shared in the FGDs, respectively. Last but not least, 
special thanks go to the research team members and those who have either directly or directly involved in supporting and assisting throughout the completion of the research and this paper.

\section{References}

1. http://www.swov.nl/rapport/Factsheets/UK/FS_Vulnerable_road_users.pdf

2. http://www.swov.nl/rapport/factsheets/uk/fs_pedestrians.pdf

3. http://apps.who.int/iris/bitstream/10665/189242/1/9789241565066_eng.pdf?ua=1

4. https://crashstats.nhtsa.dot.gov/Api/Public/ViewPublication/812124

5. Statistical Report of Road Accidents 2013 (Royal Malaysian Police, Traffic Branch, Bukit Aman, Kuala Lumpur, 2014)

6. Statistical Report of Road Accidents 2014 (Royal Malaysian Police, Traffic Branch, Bukit Aman, Kuala Lumpur, 2015)

7. A. H. Ariffin, Z. Mohd Jawi, M. H. Md Isa, K. A. Abu Kassim, S. V. Wong, Proceedings of the MIROS Road Safety Conference, 280-289 (MIROS, Kuala Lumpur, 2010)

8. https://www.jstage.jst.go.jp/article/eastpro/2011/0/2011_0_385/_pdf

9. https://www.miros.gov.my/1/dl.php?filename=Factsheet $\% 202 . p d f$

10. http://www.who.int/roadsafety/decade_of_action/plan/plan_en.pdf

11. http://www.mot.gov.my/SiteCollectionDocuments/Darat/Pelan+KJRM+2014-2020.pdf

12. http://www.mot.gov.my/en/Statistik\%20Tahunan\%20Pengangkutan/Transport\%20Stat istics\%20Malaysia\%202014.pdf

13. A. S. Al-Ghamdi, Accid. Anal. Prev. 34, 729-741 (2002)

14. H. L. Chang, T. H. Yeh, J. Transp. Eng. 132, 227-236 (2006)

15. D. M. P. Wedagama, D. Dissayanake, Journal of Eastern Asia Society for Transportation Studies 8 (2009)

16. http://www.thaiauto.or.th/2012/Automotive-Summit/doc/ppt/2015/25-615/203_AM/05.Bosch_Automotive_Summit_25062015.pdf 